\title{
PHOX2B Gene Mutation
}

National Cancer Institute

\section{Source}

National Cancer Institute. PHOX2B Gene Mutation. NCI Thesaurus. Code C135016.

A change in the nucleotide sequence of the PHOX2B gene. 